\title{
SYNTHESIS AND PROCESSING OF NANO-SCALE MATERIALS THROUGH CHEMISTRY
}

\author{
Helmut K. Schmidt \\ Institut für Neue Materialien gem. GmbH \\ Im Stadtwald, Geb. $43 \mathrm{~A}$ \\ D-66 123 Saarbrücken, Germany
}

\section{INTRODUCTION}

The sol-gel process can be considered as a method for the preparation of non-metallic inorganic materials by a chemical route. This general definition, however, does not match completely the specifics of this process since the sol phase is considered to be indispensable. The preparation of precursors for inorganic materials, for example, ceramics by precipitation processes or chemical vapor reaction to synthesize powders has been known for long times and industrially used widely as, for example, the Bayer process for the production of alumina powders. In order to make this type of processes efficient, the precipitation takes place under thermodynamic conditions, under which no disturbance of nucleation and growth takes place in order to obtain well-defined precipitates easy to be filtered or processed. Another example is the hydrothermal process, for example, developed by Degussa, or the fabrication of zirconia', where the transport mechanisms for crystal growth under elevated pressure and temperature conditions and the formation of thermodynamically stable and well crystallized phases is easier than under low-pressure, lowtemperature conditions. If nucleation and growth take place under conditions where the nuclei absorb surface charges, each nucleus grows independently and no aggregation takes place if the surface charges (related to the so-called Zeta-potential) are in the range where the resulting repulsing forces are strong enough to avoid agglomeration. Moreover, if the concentration is off the feet and the resulting concentration of particles in the liquid system is low enough to keep the distances in a range where the Stern's potential ${ }^{2}$ does not switch into attraction, colloidlal solution can be kept stable. These thermodynamical conditions, in general, are chosen for sol-gel processing in order to produce sols. The structure of these sols may consist of macromolecules, more or less polymer type, or small particles which are mainly spherical. It was found that these sols may be used for the development of coatings, and this was one of the driving forces for scientists to investigate the reaction mechanisms of the production of sols and the gelation ${ }^{3}$. Gelation, in general, takes place if sols get destabilized either by removal of the surface charges or by overcoming the critical 


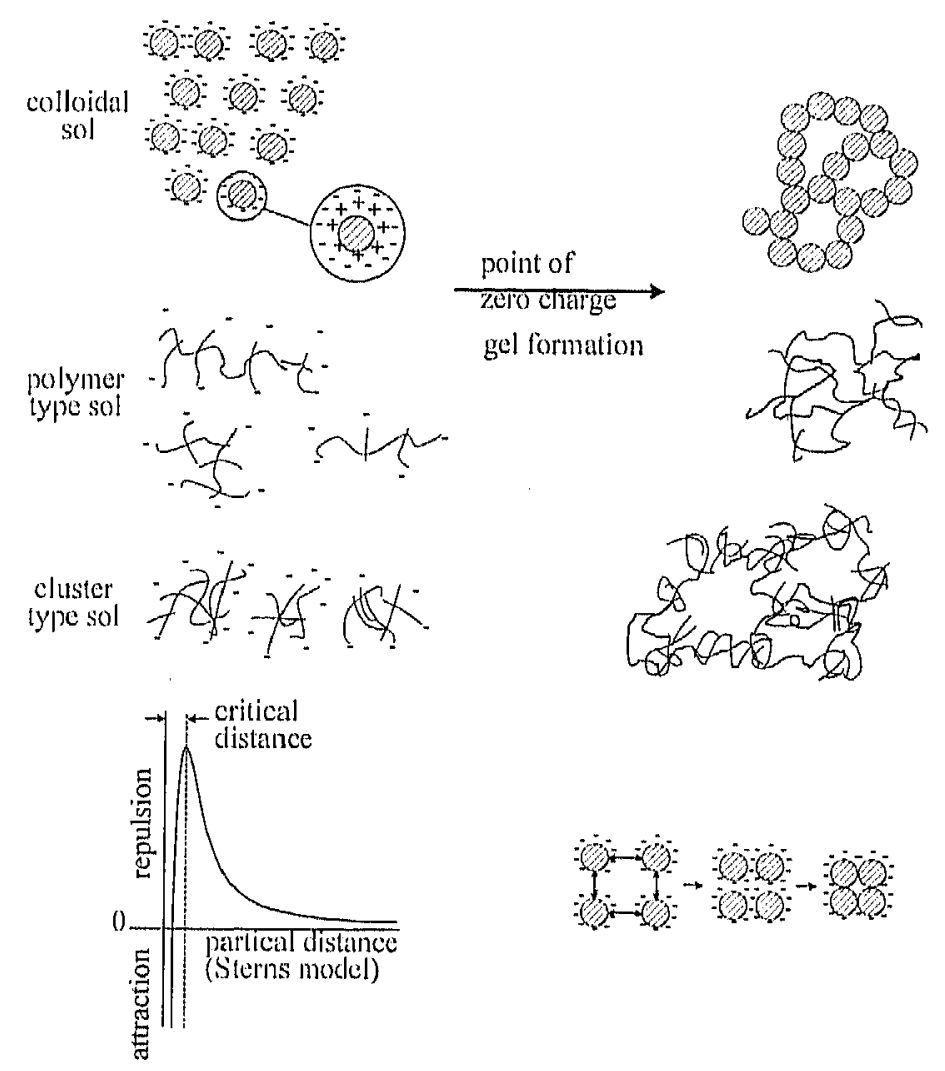

Figure 1. Scheme of the gel formation from sols by different mechanisms. a: destabilization by removal of electric charges, e.g. pH value change; b: overcoming the critical distance in Stern's model.

distance, as shown in fig. 1. The removal of surface charges is easy to be obtained by moving the system into the range of the point of zero charge, for example, by adapting the appropriate $\mathrm{pH}$ values. By upconcentration of the sol, for example, through removal of the solvent, the critical distance between the particles is overcome, and the repulsion changes to attraction. This, for example, can easily be observed by dip coating processes, as investigated in cletail by Brinker". Both mechanisms, however, lead to a more or less rather spontaneous gel formation with an irregulary shaped network with a rather high pore volume.

This consideration described above reveals also the weak points of sol-gel processing. It is very difficult to obtain high solid contents in the sol, and that leads, in general, to low density gels. The pores are, in general, filled with liquids, producing strong capillary forces and subsequent problems during drying since the mechanical strengh of gels is low ${ }^{5}$. So lilms and green bodies made from gels, in general, are fragile and of low density, In the second step, if one wants to produce dense materials from gels, high shrinkage rates have to be taken into consideration. For this reason, the sol-gel process is not considered as a reasonable method for the fabrication of ceramic parts, for example, even if sintering temperatures can be kept rather low.

One of the consequences is that sol-gel processing, in general, only is used for the labrication of thin films or particles like ceramic powders, if purely inorganic systems are envisaged, and another consequence is, that large-scale industrial applications still are the rale exception. However, one of the interesting aspects of sol-gel processing is the fact that nanoscale dimensions are "available". 
The question arises, how far these phases can be stabilized and utilized for the fabrication of materials. In this paper, some basic considerations how to achieve this target and material developments based on $\mathrm{SiO}_{2}$ nanoparticles as examples for utilization are given.

\section{THE SOL-GEL PROCESS AS A BASIS FOR NANOTECHNOLOGIES}

Based on nucleation and growth processes, in a growing system starting from a nucleus size of a few angströms, a nano-scale phase is "automatically" obtained as an intermediate. Nano-scale particles have recently gained increasing interest as intermediates for the fabrication of various new materials. In fig. 2 , some of the interesting properties of

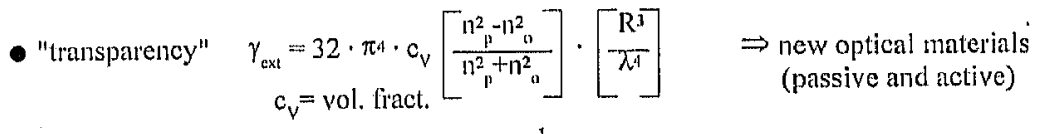

$$
\begin{aligned}
& \Rightarrow \text { Rayleigh scattering neglectable, if } \mathrm{d}<\frac{1}{20} \lambda \text { ! } \\
& \text { - quantum size eflects } \\
& \text { - surfice area } \begin{array}{c}
800 \\
8000 \\
800^{\circ}
\end{array} \rightarrow \text { several hundred } \mathrm{m}^{2}
\end{aligned}
$$

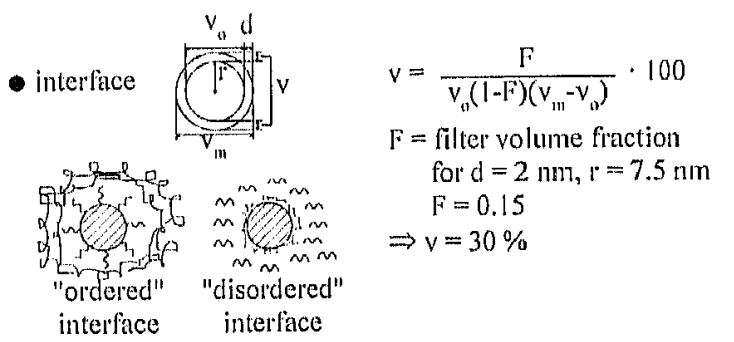

$$
\begin{aligned}
& \Rightarrow \text { aclive materials, } \\
& \text { lasers, NLO, sensors } \\
& \begin{array}{l}
\Rightarrow \text { calalysts, adsorbents, } \\
\text { sensors, binders, low } \\
\text { sintering cermuics, } \\
\text { membranes }
\end{array} \\
& \Rightarrow \text { polymer matrix nano- }
\end{aligned}
$$

Figure 2. Some interesting properties of nanoparticles and materials potential based on this.

nanoparticles are summarized. As a result of various basic properties of nanoparticles, there is a large potential for the fabrication of new materials. For this reason, it is worthwhile to investigate the usefulness of the sol-gel process for the fabrication of nanoparticle or nanoparticle-containing systems, such as composites. The simplest step in this connection is the fabrication of sols, as already described above. There is extensive literature about solgel processing which cannot be discussed here. An overview can be obtained from the conference books of Better Ceramics Through Chemistry ${ }^{6-8}$, Sol-Gel Optics ${ }^{6}$ I1 and the Workshop on Glasses and Ceramies from Gels ${ }^{12-14}$ and the literature cited therein. But only a few articles are related to the fabrication of nanoparticles ${ }^{15} .16$. One of the most difficult steps is to make use of the nano-scale particles from colloidal sols for the fabrication of materials like ceramics, composites or thick films. To achieve this, two basic problems have to be overcome: first, to increase the solid content of sols if a wet processing step directly from the solutions is desirable, and second, to avoid agglomeration in a sense that no weak brittle gels with low solid contents are produced. In addition to this, if the particles should be used for composite materials, for example, optical transparent systems, it is necessary to 
generate surface reactivities on the particles to make them compatible to the corresponding matrix system. If this can be achieved, interesting prospects exist for making many useful materials, as already indicated in fig. 1.

For these reasons, the "simple" sol-gel process by using electrostatic forces to keep the particles apart, has to be changed, and other methods have to be introduced to fabricate processable nano-scale particles. One of the concepts described in detail in ${ }^{17-18}$ is related to the fact that surfaces of very small particles react very similarly to ions in solution, as shown in different examples, e.g. in "19. It could be shown that IR spectra of complex formers like B-diketones with aluminum alkoxides do not differ from IR spectra of these complex formers absorbed to nanoparticle surfaces. This was shown with ellyyl acetoacetate complexed with aluminum alkoxides or absorbed to neno-scale boelimite particles, with propionic acid in form of altuminum propionates or absorbed to boehmite particles, or mothacrylic acid complexed to zirconia alkoxide ${ }^{211}$ or (o) adsorbed nanoparticles of $x$ irconial 21 .

This leads to the concept that it is possible to modify oxidic nanoparticles with various surface modifiers to form sol-like bonds, complex-formed bonds, and, of course, if hydrolyseable silanes are used, the formation of surface oxygen silicon bonds also is possible.

Moreover, it has been found that carrying out hydrolysis and condensation in the presence of this type of surface modifier, nucleation and growtl can be influenced to obtain appropriate particle sizes, as shown in fig. 3. The particle size distribution oblained by these processes depends on the total concentration of the system and gets narrower with decreasing solid content.
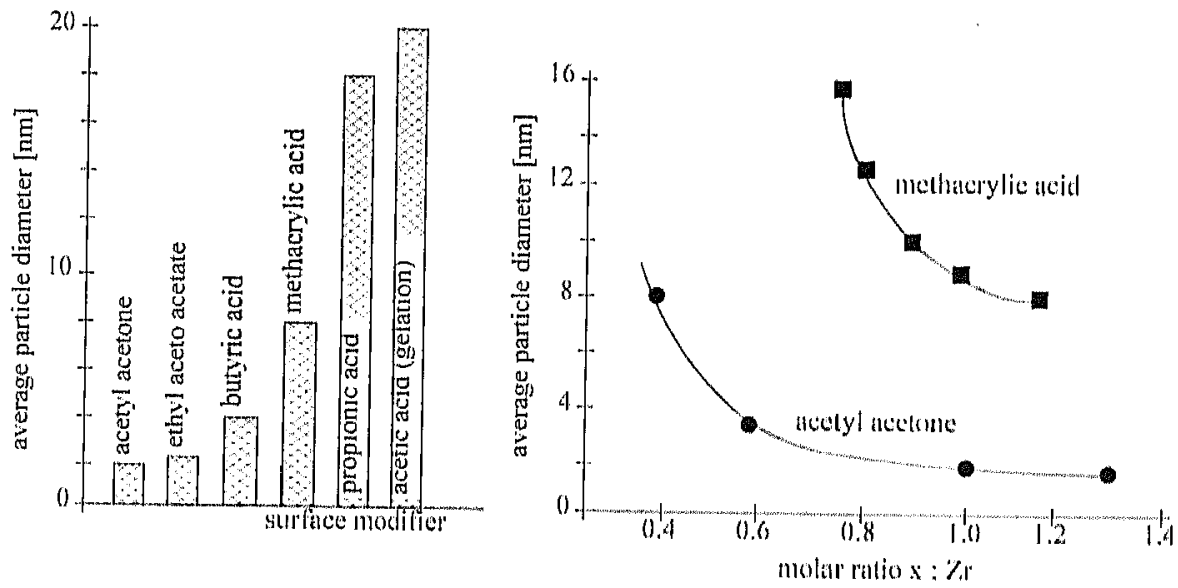

Figure 3. Examples for the tailoring of partiele size by varying the surfice modifiser concentration cluring hydrolysis and concentration; at comparison of difleerent types of modilïers; h: influence al the modifier concentration shown with acac and methacrylic acid.

In the figure, it is shown that there is a strong influence of the type of surftace modilier on the particle size, obtained with identical ratios ol surface modilisers and the dependence of' the particle size as a finction of the surface modilier concentration will acelyl acesone (acac) and methacrylic acicl as examples. As one can see from lig. 3. Here are similarities

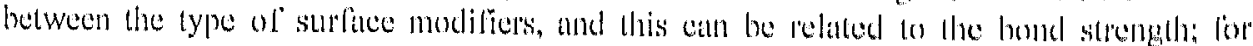
example, acetyl acetone and ethyl acetoacetate bond much stronger and morec completely to the surfice and lead to smaller particle sizes. 'This rises the hypowhesis that the surface free 
energy to be expressed by the coverage of the surface with the modifiers governs the particle size. The higher the modifier concentration, the more surface area has to be produced to reduce the surface free energy, and this leads to smaller particles. In fig. $3 b$, this is confirmed by the influence of the surface modifier concentration on the particle size. The higher the concentration is, the more surface to bind the surface modifier has to be produced, which also leads to decreasing particle size with increasing surface modifier concentration.

This surface modification not only can be used to produce size-controlled species, but, for example, the methacrylic acid bonded to the particle surface can be used for polymerizing the particles into polymer networks ${ }^{22-24}$. It could be shown that many new nanocomposites can be prepared by using this approach. Due to the small particle sizes, which can be obtained by choosing the appropriate parameter, as shown in fig. 2 , the particle size of the zirconia can be kept in the range between 2 and $5 \mathrm{~nm}$, and optical composites can be obtained.

If photopolymerization is used, it can be carried out with common photo catalysts ${ }^{23}$ and this has been investigated by photodifferential scanning calorimetry. It could be shown that the reactivity in these complex systems with nanoparticles is surprisingly high, and that conversion rates at elevated temperatures $\left(120^{\circ} \mathrm{C}\right)$ above $90 \%$ are obtained, as determined by infrared spectroscopy. Films produced from these composites can be used for photolithographic patterning, such as laser writing or mask aligner techniques ${ }^{25}$. If masks are used, and if the film is irradiated through masks, inhomogeneities are introduced into the materials, leading to the so-called Colburn-Haines effect. Through the chemical potential produced by the consumption of double bonds in the irradiated areas, a mass transport occurs to compensate the loss. It was of interest, how far methacrylic acid-covered zirconia nanoparticles are involved in these diffusion processes. For this reason, experiments have been carried out the details of which are described elsewhere ${ }^{26}$ to find out whether the coated nanoparticles are mobile or not. Zirconia nanoparticles seemed to be of special interest because they exhibit a relatively high refractive index compared to the polymeric matrix. In order to separate the diffusion of the unpolymerized matrix monomers from the unpolymerized methacrylic bond to the particle surface, methacryloxysilanes have been chosen as monomers since these double bonds fixed to the silicon can be immobilized by the formation of an inorganic backbone by hydrolysis and condensation, which is a reaction not affecting the organic polymerization. In fig. 4, the schematics of this process is shown, as well as the refractive index differences to be obtained by this method. As one can see, the diffusion of nanoparticles with a refractive index higher than that of the matrix should lead to an index gradient after full area polymerization.

Refractive index measurements before and after polymerization in the different areas and as a function of the $\mathrm{ZrO}_{2}$ content revealed that in $\mathrm{ZrO}_{2}$ containing films, a $\Delta_{\mathfrak{n}}$, which was built up to $2.10^{-2}$, is found, whereas in $\mathrm{ZrO}_{2}$ free films, after full area polymerization, the $\Delta_{11}$, which was built up between unpolymerized and polymerized zones, disappears. In fig. 5 the results are shown. There is a clear connection between the Si methacryloxy : $\mathrm{Zr}$ ratio (B) and the maximum $\Delta_{11}$. If no $\mathrm{ZrO}_{2}$ is present, $\Delta \mathrm{n}$ becomes zero after full area polymerization. Before full area polymerization, the appearant $\Delta_{n}$ results from the higher density of the polymerized zones. With $r$ equal to 0.1 , the maximum $\Delta_{n}$ is obtained, which is attributed to a high diffusion coefficient as a consequence of a relatively low $\mathrm{ZrO}_{2}$ nanoparticle concentration $\left(\mathrm{ZrO}_{2} \approx 2 \mathrm{~nm}^{26}\right)$. With increasing $\mathrm{ZrO}_{2}$ concentrations, the $\Delta_{\mathrm{n}}$ gets lower and the time period to reach the maximum decreases, indicating a decreasing of the diffusability of $\mathrm{ZrO}_{2}$ particles. The diffusion comes to a stop with the propagation of the polymerization. In fig. 6 the $\mathrm{Zr}$ EDX line scan of a resulting optical grating is shown. The line scan shows 


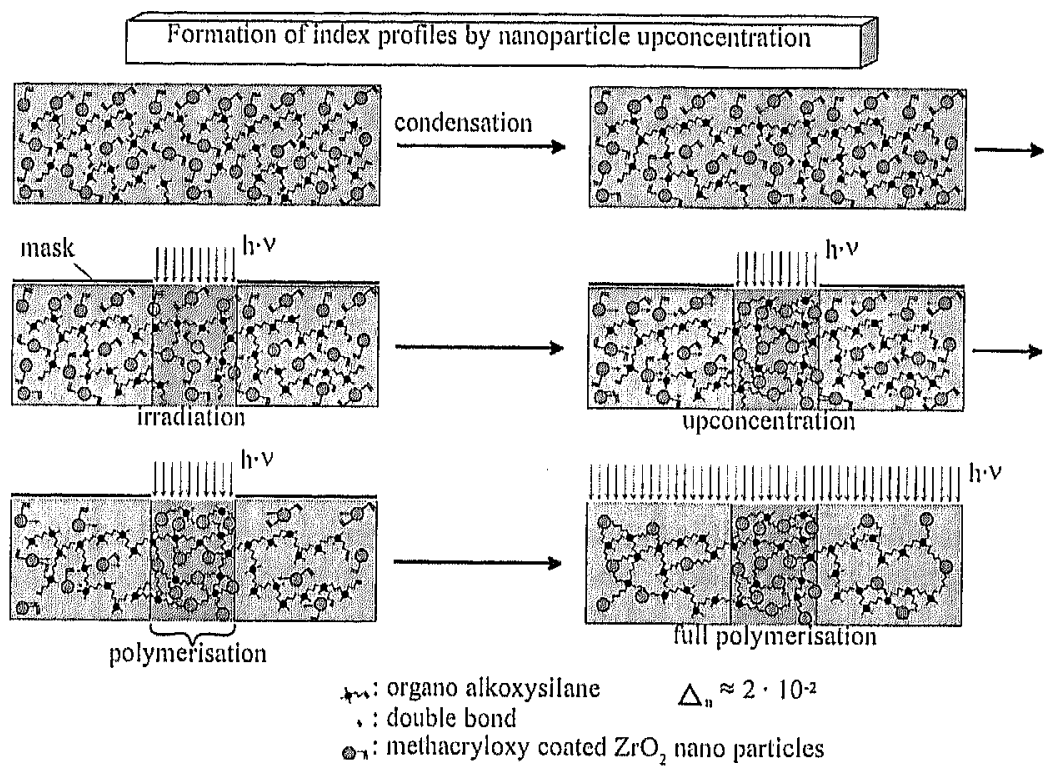

Figure 4. Draft of the principles of the diffusion process initiated by the consumption of the $\mathrm{ZrO}_{2}$ bonded melhacryloxy grouping by polymerization.

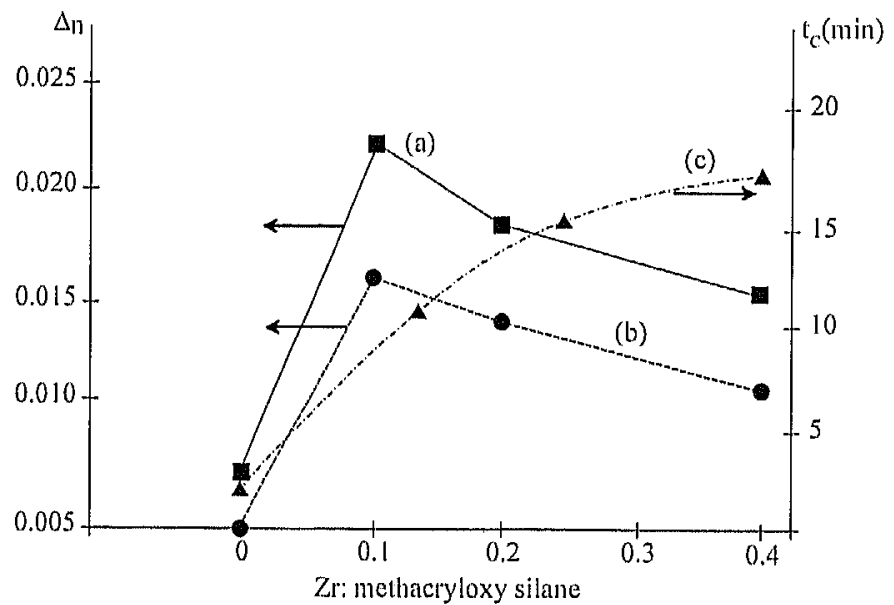

Figure 5. Development of $\Delta_{n}$ values in photopolymerized fillns prepared from methacryloxy silane, Zr(OBu and methacrylic acid ${ }^{\text {niler } 2.3}$. Curve (a) shows the $\Delta_{11}$ values after 15 min UV exposure throtigh a $5 \mu \mathrm{m}$ mask and curve (b) after an additional full area polymerization as a function of the $\mathrm{Zr}$ : Si methacryloxy ratio i"; curve (c) shows the time required to obtain the maximum value of the diffraction efficiency as a function of the $\mathrm{zr}$ : Si rillio, too. 


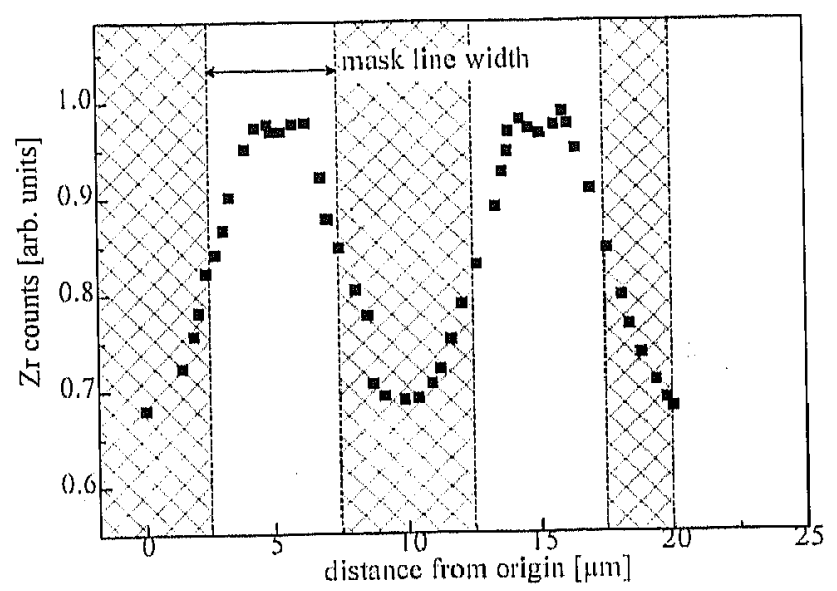

Figure 6. $\mathrm{Zr}$ EDX line scan over a $\mathrm{ZrO}_{2}$ nanocomposite film after mask aligner and subsequent full area photopolymerization "liter 27 .

that the $\mathrm{Zr}$ concentration follows very well the mask width of $5 \mu \mathrm{m}$ and proves that $\mathrm{Zr}$ really diffuses into the preliminary irradiated zones. This process can be used for holographic grating or fresnel lens fabrication as well as for clata storage. By leaving residual charges on the particles and employing electrodes, the particles can be moved in direction to the anode, and gradients over larger areas are obtained. As shown in ${ }^{26}$, a gradient index step of 0.07 in lenses of about $1.5 \mathrm{~cm}$ in diameter was obtained. This method opens the possibility of tailoring gradients in larger components according to the employed electric field.

\section{MATERIAL DEVELOPMENTS}

\section{Ceramic Powders}

As described elsewhere ${ }^{18}$, by using the surface modifier appronch, a large number of non-agglomerated particles have been synthesized and used for materials fabrication. An overview is given in table 1 . Moreover, by combination of the CGP with solvothermal techniques ${ }^{29}$, well crystallized particles $\left(5 \mathrm{Y}^{2} \mathrm{ZrO}_{2}\right)$ are produced by continuous flow methods. An example for the crystallinity and uniformity is shown in fig. 7.

\section{Binder materials}

As shown in ${ }^{18}$, a large variety of surface modifiers can be employed. Especially colloidal silica as available from various industrial companies is a very interesting sol-gel precutsor because it is a commercial product and cheap. Moreover, the particle size commercially available ranges between 5 and $30 \mathrm{~mm}$. These products, in general, are charge stabilized, and from all these problems known from conventional sol-gel processing occur. So, surface modification of these particles seems to be an interesting route for novel materials from $\mathrm{SiO}_{2}$. One of the interesting principles of substituting charge stabilization by chemical stabilization is to control the particle-to-particle interaction. From the application point of view, the addition of $\mathrm{SiO}_{2}$ nanoparticles to sol-gel processed materials has led to interesting hard coating materials ${ }^{35-36}$. Based on these considerations, a surface modifieation method has been developed by Jonschleer" ${ }^{37}$, which showed that colloidal silica processed by this route leads to the possibility of increased solid contents without gelation. The scheme of the reaction is shown in fig. 8. As a consequence of the reduced particle-tom- 


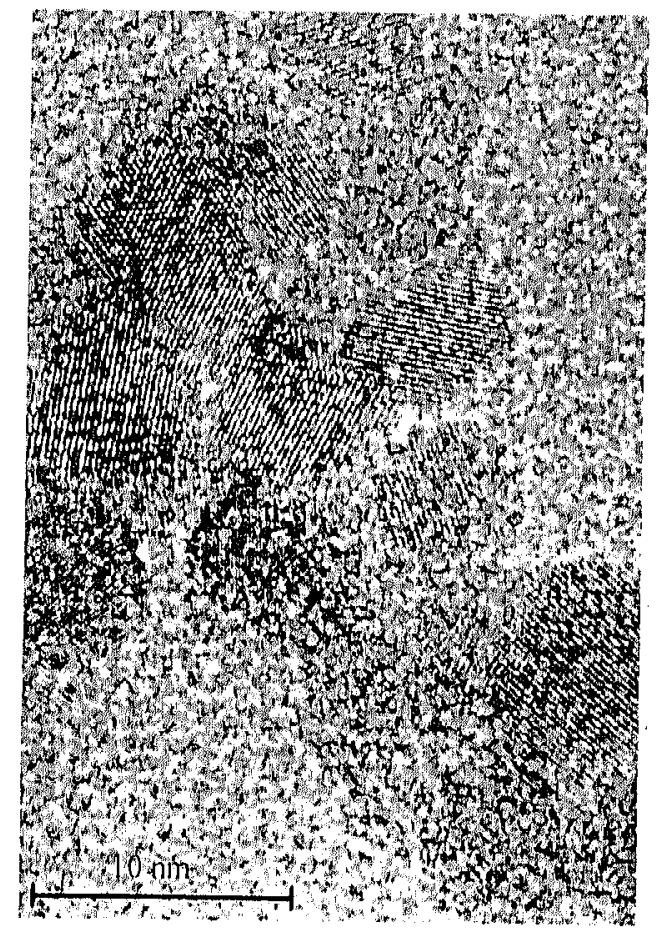

Figure 7. Electron microscopic image of $5 \mathrm{Y}-\mathrm{ZrO}_{2}{ }^{\text {niter }}: 0$

particle interaction and increased solid content, it was possible to produce thick films by simple dip coating steps from these sols ${ }^{35,38}$, and wet coating thicknesses of 10 to $20 \mu \mathrm{m}$ and densified coating thicknesses of up to $10 \mu \mathrm{m}$ became possible in a one-step dip-coating process. After the formation of an emulsion, the system becomes one-phasic by the formation of alcohol by hydrolysis which acts as agent to provide sufficient solubility for the water phase. By variation of $\mathrm{R}^{\prime}$ and the concentration of TEOS, R'Si(OR) $)_{3}, \mathrm{H}_{2} \mathrm{O}$ and $\mathrm{H}^{+}$, the binding properties and the reaction rate could be adapted to various applications.

One of the most interesting properties for the application of nanoparticulate systems is the strong particle-to-particle interaction, which sums up to considerable binding forces per volume unit. But after "gelation", this does not lead to strong gels because the overall density of gels is very low. In fully densified inorganic materials, the overall binding force is high, leading to brittle materials with low fracture toughness. With respect to sealants, which require properties like good stress dissipation, inorganic materials with their low

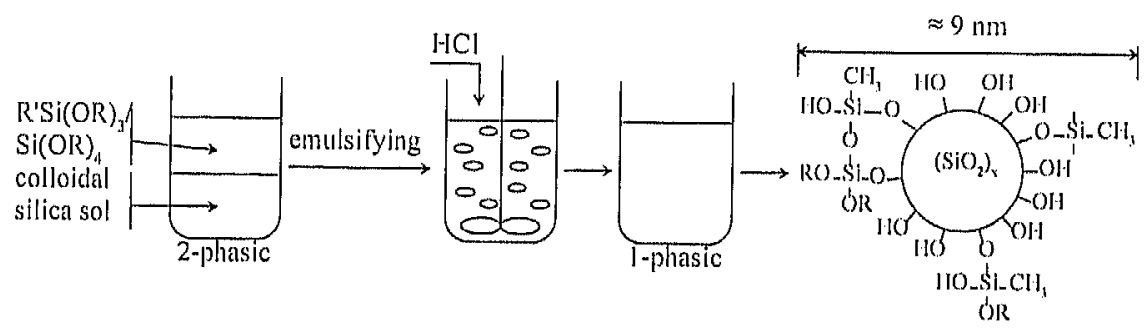

Figure 8. Reaction principle of the formation of partially surface-modified $\mathrm{SiO}_{2}$ sols. $\mathrm{R}^{\prime}=$ methyl, pheny $\left.\right|^{37}$. 
Table 1. Overview over nanoparticles fabricated by the surface modifier approach (controlled growth process, CGP) (details are published elsewhere) ${ }^{18,19,28-34}$.

\begin{tabular}{|c|c|c|c|c|}
\hline System & $\begin{array}{c}\text { Primary } \\
\text { Particle Size } \\
(\mathrm{nm})\end{array}$ & $\begin{array}{c}\text { Crystal } \\
\text { Structure }\end{array}$ & $\begin{array}{l}\text { Doping } \\
(\mathrm{mol} \%)\end{array}$ & $\begin{array}{l}\text { Synthesis } \\
\text { Technique }\end{array}$ \\
\hline $\mathrm{ZrO}_{2}$ & $5-10$ & $\begin{array}{l}\text { monoclinic } \\
\text { tetragonal } \\
\text { cubic }\end{array}$ & $\begin{array}{c}\mathrm{Y}^{3+}, \mathrm{Pr}^{3+7}, \mathrm{Sc}^{3+7} \\
0-8\end{array}$ & $\begin{array}{l}\text { controlled growth } \\
\text { microemulsion }\end{array}$ \\
\hline $\mathrm{SnO}_{2}$ & $3-5$ & Cassiterite & $\begin{array}{l}\mathrm{Sb}^{3+1} \\
0-10\end{array}$ & controlled growth \\
\hline PZT & $10-20$ & Perowskite & & controlled growth \\
\hline $\mathrm{Y}_{2} \mathrm{O}_{3}$ & $10-20$ & cubic & $\begin{array}{c}\mathrm{Eu}^{3+} \\
0-3\end{array}$ & controlled growth \\
\hline $\mathrm{Y}(\mathrm{OH})_{3}$ & 20 & amorphous & $\begin{array}{c}\mathrm{Eu}^{3+} \\
0-3\end{array}$ & controlled growth \\
\hline $\mathrm{TiO}_{2}$ & $5-50$ & $\begin{array}{l}\text { Anatase } \\
\text { Rutile }\end{array}$ & $\begin{array}{l}\mathrm{Al}^{3+} \\
0,5\end{array}$ & controlled growth \\
\hline $\mathrm{In}_{2} \mathrm{O}_{3}$ & $10-30$ & hexagonal & & controlled growth \\
\hline ITO & $10-30$ & hexagonal & $\begin{array}{l}\operatorname{Sn}^{4+4} \\
1-10\end{array}$ & controlled growth \\
\hline $\mathrm{a}-\mathrm{Al}_{2} \mathrm{O}_{3}$ & 60 & Corundum & & controlled growth \\
\hline $\begin{array}{c}\text { HAP } \\
\text { (hydroxy } \\
\text { apatite) } \\
\end{array}$ & $5-30$ & hexagonal & & controlled growth \\
\hline $\begin{array}{c}\mathrm{Fe}_{2} \mathrm{O}_{3} / \mathrm{Fe}_{3} \\
\mathrm{O}_{4}\end{array}$ & $5-10$ & $\begin{array}{l}\text { Magnetite } \\
\text { Maghemite }\end{array}$ & & $\begin{array}{l}\text { microemulsion } \\
\text { controlled growth }\end{array}$ \\
\hline $\mathrm{BaTiO}_{3}$ & $50-100$ & Perowskite & & controlled growth \\
\hline
\end{tabular}

fracture toughness are not the best choice. If inorganic sols, for example, are used for glass liber binding, brittle products are obtained which are not elastic and easily can be crumbled to dust. If organic groupings are introduced by $\mathrm{SiO}_{2}$ nanoparticle surface modification, clearly depicts that the uncovered stainless steel is covered with a dark oxidation layer. The coating thickness is kept between 3 and $5 \mu \mathrm{m}$, and this is sufficient to obtain oxiclation protection, but also protection from altacks from acids. Due to its low thickness, the coatings are flexible, and shaping after coating is possible. The abrasion resistance of this glass-like coating is comparable to float glass and 1000 cycles taber abrader with an alumina-filled rubber wheel $(500 \mathrm{~g})$ show that a scratching of the surface is hardly detectable. For decoration purposes, the coatings can be outfitted with metal colloids ${ }^{42}$ and transparent coloured coatings on any stainless steel surface (e.g. brushed, sanded) for architectural and other applications have been fabricated. In fig $9 \mathrm{~b}$ (1) optical waveguides fabricated by rapid annealing (RA) and in $9 \mathrm{~b}(2)$ the formation of micropatterns by embossing are shown ${ }^{38}$. By an appropriate time/temperature profile, fully densiffed $\mathrm{SiO}_{2}$ layers without residual stress at room temperature are obtained by RA. In fig. $10 \mathrm{~b}(2)$ it is remarkable that densification takes place without loosing the preciseness of the patterns.

In fig. 9c composites made from natural libers like straw or cotton are slown. Due to the specific coatings of the nanoparticles, which have polar as well as unpolar groupings, even straw, which is diffieult to bind with most of the commercial sealants, can be bonded to high-strength composites in a fast process. Composites with straw, for example (only polyurethane is suitable), show a density of about $0.2 \mathrm{~g} / \mathrm{cm}^{3}$ and a pressure strength of 4 


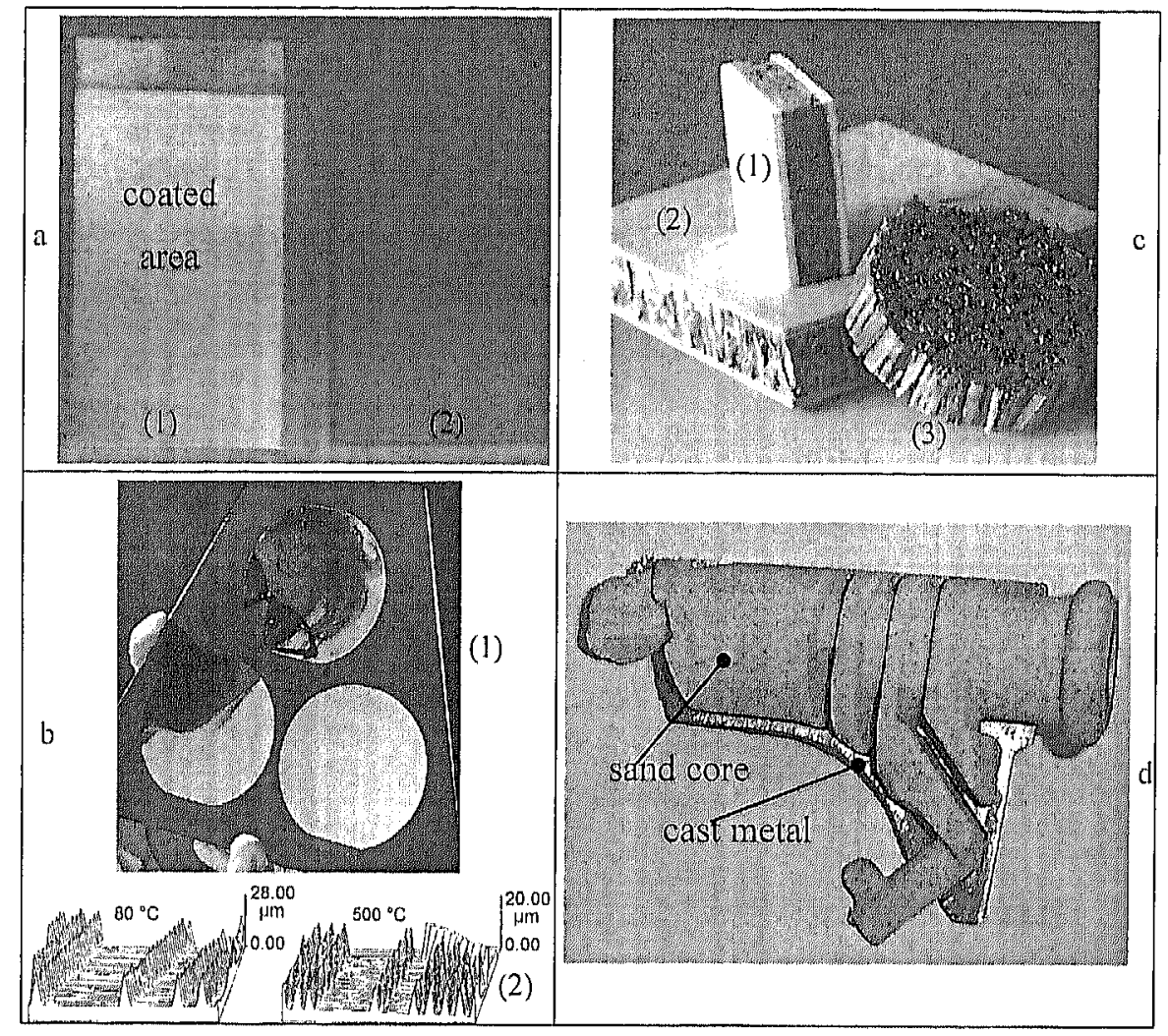

Figure 9. Products made by $\mathrm{SiO}_{2}$ nanoteclnologies. a: Corrosion, staining and abrasion resistant coating on stainless steel; samples heated to $900^{\circ} \mathrm{C}$ for $1 \mathrm{hr}$; (1) coated, (2) uncoated sample; b: (1) optical $\mathrm{SiO}_{2}$ waveguides on $\mathrm{Si}$; (2): $\mathrm{SiO}_{2}$ parts made by embossing of $\mathrm{SiO}_{2}$ gels before and after densification; c: composite materials made from $\mathrm{SiO}_{2}$ binders and natural products, (1) plywood/cotton; (2) straw with and (3) without plywood; d: core sand for casting water taps from $R$ brass.

$\mathrm{MPa}$, which is extraordinately high for this type of low-density materials ${ }^{41,43}$ and, in addition to this, are inflammable.

Similar to the fiber bonding process, it is also possible to bind core sands, as shown in fig. 9d. Core sands are used for metal casting with complex shapes and have to be removed easily after the casting process is finished. For core sands, the phenolic resins in use cause serious environmental problems. With a new $\mathrm{SiO}_{2}$-based binding system, these problems can be reduced almost to zero since only a very small concentration of organics are present in the system, which burn out very easily to form carbon clioxide and water.

In casting technology for parts where cores are needed, about $30 \%$ of the cost at present result from environmental issues (e.g. washing of the gases from phenolic resin decomposition, recycling of used core sands covered with pyrolysis products of phenolic resins). In these cases, the use of the new inorganic binder will have an interesting potential in foundry industry. The technological advantage of the binder compared to water glass based binder in core sand teclunology is its tailorable curing rate, which already has been adapted to technical requirements in the process using heated moulds (hot box technology). 


\section{CONCLUSIONS}

As a conclusion, it is to say that chemistry provides very interesting tools for the development of new materials through nanotechnologies. Compared to ofher techniques, the fabrication of nanoparticles can be designed through chemical engineering which, in general, allows the production of low-cost, high-volume materials.

As one of the most important topics, the surface modification of nanoparticles has been identified. Through these surface modification, the interfacial free energy between the nanoparticles' surface and the surrounding matrix can be reduced to a level that the particles are well-dispersed in the matrix. This leads to the concept of new optical materials, introducing the physical properties of materials which, in general, cannot be used for opticals in this type of composites.

Aside from optics, nanoparticles open up interesting industrial applications, e.g. in the form of binders, for polymers, for hard coatings, and even for ceramics. Chemical nanotechnologies seem to be at their infancy, but lirst products on the market already have shown their usefulness.

\section{REFERENCES}

1. W. Kriechbaum, P. Kleinschmitt and D. Peukert, in Ceramic Transactions $1 \Lambda$, Ceramic Powder Science. Ed.: Am. Ceram, Society, Westerville/Ohio, USA, 146 (1988).

2. O. Stern, Z, Elcklrochem, 508 (1924).

3. C.J. Brinker and G.W. Scherer, Sol-Gel Science: the Physics and Chemistry of Sol-Gel Processing, Acadenic Press, Boston (1990).

4. C.J. Brinker, A.J. Hurd, G.C. Frye, K.J. Ward, C. S. Aslaley, Sol-gel thin film formation, J. Non-Cryst, Solids 121:294 (1990).

5. J. Zarzycki, Synthesis of glasses from precursor: bulk and film - a comparison, Proc. of the European Meeting Inorganic Coutings on Glass, P. Picozzi, S. Santucci, P. Boattini, L. Massarelli and V. Scopa (eds,), Soietả Italiana Vetro, L'Aquila, Italy, 149 (1.988).

6. Better Cercinic.s Through Chemistry, K, Mat. Res. Soc. Symp. Proc. Vol. 271, M. J. Hampden-Smitl, W. G. Klemperer and C. J. Brinker (eds.), Materials Research Society, Pittsburgh/PA (1992).

7. Better Ceramics Through Chemistry VI, Mat, Res. Soc. Symp. Proc. Vol. 346, A. K. Cheetham, C. J. Brinker, M. L. Mecartncy and C. Sanchez (eds.), Materials Research Society, Pittsburgh/PA (1994).

8. Betler Ceramics Through Chemistry VII, Mat. Res. Soc. Symp. Proc. Vol. 435, B. K. Coltraill, C. Sancliez, D. W. Schaefer and G. L. Wilkes (eds.), Materials Research Society, Piltsburgh/l'A (1996)

9. SPIE Sol-Cel Optics l, I. D. Mackenzie and D. R. Ulirich (eds.), Vol. 1328, SPIE, Beilinglom/WA, USA (1990).

10. SPIE Sol-Gel Opticis II, J. D. Mackenzie (ed.), Vol. 1758, SPIE, Bellingham/WA, USA, 1902.

11. SPIE Sol-Gel Oplics III, J. D. Mackenzie (ed.), Vol, 2288, SPIE, Bellingham/WA, USA, 1994.

12. L. Esquivias, eds, 6th International workshop on glasses and ceranics from gels, 1991, Seville, Spain, in J. Noin-Crysl. Solids 147/148 (1992),

13. J. Livage, ed., 7th International workshop on glasses and ceranics from gels, 1993, Paris, France, in $J$. Sol-Gel Science and Technology 2:1/3 (1994).

14. R.M. Almeida, ed., 8th International workshop on glasses and ceramics from gels, 1995, in J. Sol-Gel Science and Technology 8:1/2/3 (1997).

15. S. Hirano, In-situ control of microstructures of ceranic composites, Funtai Oyobi Funmatsu Yakin $39(12): 1093-9(1992)$.

16. C. Sanchez, Molecular design of hybrid organic-inorganic nano-composites made via sol-gel chemistry, oral presentation in: Organic//norganic Polymer Systems, Division of Polymer Chennistry, Inc., American Chemical Sociely, Napa Valley (1995).

17. H. Schmidt, Organically modiffed silicales and cermics is two-phasic systems: synthesis and processing, J. Sol-Gel Science and Technology 8 No, 1/2/3:557 (1007).

18. H. Schmidt, "Relevance of sol-gel methods for synthesis of fine particles", KONA Powder and Partiele, No. 14, 92-103(1996). 
19. R. Naß and H. Sclumidt, Formation and properties of chelated alumiumalkoxides, in: Ceramic Powder Processing Sciencs, H. Hausner, G. L. Messing and S. Hirano, eds., Deutsche Keranische Gesellschaft e. V., Koln, $69-76(1989)$.

20. M. Popall, H. Meyer, H. Schmidt and J, Schulz: Inorganic-organic composites (ORMOCERs) as structured layers for microelectronics, Mal. Res. Soc. Symp. Proc. 180:995 (1990).

21. H. Schmidt, Application of Ormocers, in: Ceramic Transactions Vol. 55: Sol-Gel Science and Technology, E. Pope, S. Sakka and L. Klein, eds., American Ceramic Society, Westerville/Ohio (1995).

22. H. Schmidt, R. Kasemann, T. Burkhart, G. Wagner, E. Arpac and E. Geiter, Inorganic-organic hybrid coatings for metal and glass surfaces, in: ACS Symmosinm Series No. 585: Hybrid Organic-Inorganic Composites, J. E. Mark, C. Y.-C. Lee and P. A. Bianconi, eds., American Chemical Society, Washington (1995).

23. C. Becker, M. Zalmhausen, H. Krug and H. Schmidt, Characterization of the photopolymerization kinetics of inorganic-organic nanocomposite materials by photo-DSC, in Ceramics Transactions Fol. 55: Sol-Gel Science and Technology, E. Pope, S. Sakka and L. Klein, eds., American Ceramic Society, Westerville/Ohio (1995)

24. R. Kasemann and H. Schmidt, "Coatings for mechanical and chemical protection based on organicinorganic sol-gel nanocomposites", New Journal of Chemistry, Vol. 18, $\mathrm{N}^{\circ} .10,1117-1123,1994$.

25. F. Tiefensee, Ph. D. Thesis, University of Saarland, Saarbrucken (1994).

26. H. Sclunidt, Entwicklung, Mikrostrukturierung und Anwendung von Keramik-polymer-Nanokompositen, in Proc. Werkstoffwoche 1996, Symp. 9, DGM-Informationsgesellschaft mbH (in print).

27. F. Tiefensee, P. W. Oliveira and H. Schmidt, Organic-inorganic composite materials; optical properties of laser-atterned and protective-coated waveguides, in SPIE Proc. Sol-Gel Optics 1758:448 (1992).

28. R. Naß, D, Burgard, private communication.

29. D. Burgard, R. Naß and H. Schmidt, German Offen No. DE 19515820 A 1, 04-29-95.

30. H. Schmidt, R. Naß and D. Burgard, Verfahren zur Herstellung nanoskaliger Oxidleilchen, European Patent No. EP 0587672 BI, 02-14-96.

31. D. Burgard, Master's Thesis, University of Saarland, Saarbritcken, Germany (1992).

32. D. Burgard, C. Kropf; R. Naß and H. Schmidt, Routes to deagglomerated nanopowder by chemical synthesis, in Better Ceramics Through Chemistry VI, Mat. Res. Soc. Symp. Proc. Vol, 346, A. K. Cheetham, C. J. Brinker, M. L. Mecartney and C. Sanchez (eds.), Materinls Research Society, Pittsburgh/PA 346:101 (1994).

33. D. Burgard, R. Naß and $\mathrm{H}$, Schinidt, Synthesis and colloidal processing of nanocrystalline $\left(\mathrm{Y}_{2} \mathrm{O}_{3}\right.$ stabilized) $\mathrm{ZrO}_{2}$ powders by a surface free energy controlled process, in Mat. Res, Soc., Symp. Proc., Pittsburgh/PA, 432:113(1997).

34. D. Burgard, R. Drumm, R. Naß and H. Schmidt, Herstellung und Verarbeitung von nanoskaligem (stabilisiertem) $\mathrm{ZrO}_{2}$ lber einen kolloid-chemischen Prozeß, in Proc. Werkstoffwoche 1996, Symp. 6, G. Ziegler, H. Cherdron, W. Hermel, J. Hirsch and H. Kolaska (eds.), DGM-Informationsgesellschaft mbH, Frankfurt/M. (1997)

35. R. Kasemann, H. Sclımidt, E. Arpac and V. Gerhard, German Offen No. DE 4338361 A 1, 11-10-93.

36. G. A. Patel, C. Park, S. J, Kubisen, United States Patent No. 5,41 I,807, 05-02-95.

37. G. Jonschker, Master's Thesis, University of Salarland, Saarbr(licken (1992).

38. M. Mennig, G. Jonschker and $\mathrm{H}$. Schmidt, Sol-gel derived thick $\mathrm{SiO}_{2}$ coatings and their thermomechanical and optical properties, in SPIE Proc. Sol-Gel Optics 1758:125 (1992).

39. M. Mennig, G. Jonschker and H. Schmidt, Verfalren zur Herstellung von Glas mit verbesserter Langzeitstandfalhigkeit bei erhöhten Temperaturen, European Patent No. EP 0642475 BI, 06-19-96.

40. M. Mennig, G. Jonschker, H. Schmidt and P. Kallanek, Flame retardent coatings on glass, Glas-Ingenieur 3:54 (1994).

4I. G. Jonschker, Ph. D. Thesis, University of Saarland, Saarbrlicken (in print).

42. INM brochure "Edelstahl in neuem Gewand", Sarbricken (1997).

43. G. Jonscliker, private communication. 